\title{
Effect of single-chain ovine gonadotropins with dual activity on ovarian function in sheep
}

\author{
Heloisa M Rutigliano ${ }^{1,3}$, Betty M Adams ${ }^{1}$, Albina Jablonka-Shariff ${ }^{2}$, Irving Boime ${ }^{2}$ and \\ Thomas E Adams ${ }^{1}$ \\ ${ }^{1}$ Department of Animal Science, University of California, Davis, One Shields Avenue, Davis, California 95616, USA, \\ ${ }^{2}$ Departments of Developmental Biology and Obstetrics and Gynecology, Washington University School of Medicine, \\ Campus Box 8103, 660 South Euclid Avenue, Saint Louis, Missouri 63110, USA and ${ }^{3}$ Department of Animal, \\ Dairy and Veterinary Sciences, School of Veterinary Medicine, Utah State University, 4815 Old Main Hill, \\ Logan, Utah 84322, USA
}

Correspondence should be addressed to H M Rutigliano; Email: hrutigliano@gmail.com

\begin{abstract}
We examined the half-life and biological activity of two single-chain proteins that combined portions of ovine FSH and $\mathrm{LH}$. We proposed the hypothesis that these chimeric proteins would display LH and FSH activities and would promote follicle maturation in ewes. Estrus activity was synchronized using progestogen-impregnated vaginal pessaries. To negate the impact of endogenous $\mathrm{LH}$ and $\mathrm{FSH}$, animals received serum-containing antibodies against GNRH 1 day before pessary removal (PR). At PR sheep (five animals per group) received a single injection (10 IU/kg, i.v.) of either the ovine-based (oFcLc $\alpha$ ) gonadotropin analog, an ovine-based analog containing oLH $\beta$ truncated at the carboxyl terminus $(\mathrm{oFcL}(\Delta \mathrm{T}) \mathrm{c} \alpha)$, or a human-based gonadotropin analog (hFcLc $\alpha)$. Control animals received a comparable amount of gonadotropin-free protein. Ovulation was induced 3 days after PR using human chorionic gonadotropin (1000 IU, i.v.). Ovaries were collected 11 days after PR. Neither estradiol $\left(E_{2}\right)$ or progesterone $\left(P_{4}\right)$ production, development of preovulatory follicles or corpora lutea $(\mathrm{CL})$ were noted in control animals receiving gonadotropin-free protein. Significant increase in the synthesis of $E_{2}$ and $P_{4}$ was noted in sheep receiving the dually active gonadotropin analogs. The number of CLs present 11 days after PR was significantly increased in sheep receiving the chimeric glycoproteins compared with control animals. The magnitude of the secretory and ovarian responses did not differ between hFcLc $\alpha$ and oFcLc $\alpha$ or between oFcLc $\alpha$ and oFcL( $\Delta \mathrm{T}) \operatorname{c} \alpha$. Immunoactivity of LH and FSH was low in control animals, but was significantly elevated in sheep receiving the gonadotropin analogs. In conclusion, ovine-based gonadotropin analogs are functionally active in sheep and a single injection is adequate to induce the development of multiple ovulatory follicles.

Reproduction (2014) 148 129-136
\end{abstract}

\section{Introduction}

Exogenous gonadotropins are commonly used to treat reproductive disorders, induce ovulation during the anestrus season, advance puberty, and/or facilitate superovulation and estrus synchronization. The gonadotropin preparations most often used by animal producers are equine chorionic gonadotropin (eCG) or human chorionic gonadotropin (hCG) and luteinizing hormone (LH) and follicle-stimulating hormone (FSH) of porcine or ovine origin. Several investigators have noted that the potency and purity of tissue-derived gonadotropins can vary extensively from batch to batch (Kanitz et al. 2002). For example, the FSH activity of eCG varies dramatically with the stage of pregnancy of the donor mares. The functional life of exogenous gonadotropins also varies widely. In general, placental gonadotropins are long acting while pituitary-derived gonadotropins have a relatively short duration of response. In addition, tissue-derived gonadotropin preparations may harbor pathogenic agents and, as a consequence, may be vectors for infectious diseases (Galli et al. 2003).

Gonadotropins produced by appropriately transfected cells in culture obviate many of the concerns associated with tissue-derived gonadotropins. Recent technical innovations by Boime et al. (Kanda et al. 1999) have further enhanced the efficacy of recombinant gonadotropins by generating single-chain variants that incorporate multiple subunit domains into a singular peptide chain. Our previous work demonstrated that the singlechain analogs of human $\mathrm{LH}$ and human FSH were active in sheep. We also demonstrated that a multicomponent construct that included $\mathrm{LH}$ and FSH subunit domains in the single-chain motif expressed dual activity ( $\mathrm{LH}$ and 
FSH activities) in sheep (Lemke et al. 2008). The subunit domains in the single-chain constructs are combined using a linker sequence encoding the carboxy-terminal portion (CTP) of hCG $\beta$. Incorporation of the CTP domain into chimeric gonadotropin analogs extends the functional life of the hormone (Bouloux et al. 2001). In addition, production of single-polypeptide chain gonadotropins eliminates the need for subunit dimerization, a rate-limiting step in synthesis of endogenous gonadotropin (Sugahara et al. 1996).

Follicle growth and ovulation depends on the coordinated action of FSH and $\mathrm{LH}$, with supplemental FSH playing a critical role in rescuing subordinate follicles from atresia and, therefore FSH activity is essential for superovulation. The coordinated and synchronized nature of the actions of $\mathrm{LH}$ and $\mathrm{FSH}$ in the maturation of follicles suggests that it may be advantageous to incorporate both activities into a single molecule. However, the relative proportion of $\mathrm{LH}$ and FSH activities in gonadotropin preparations with dual activity can affect ovarian response. Indeed, high LH content in FSH preparations may cause premature luteinization of developing follicles (Opavsky \& Armstrong 1989) or improperly timed ovulation (Callesen et al. 1987). Thus, the relative levels of LH and FSH activities in single-chain analogs with dual activity may significantly affect the number and viability of oocytes released at ovulation. The work of GarciaCampayo \& Boime (2001) suggests that the heptapeptide truncation decreases $\mathrm{LH}$ activity without altering the FSH activity of dually active gonadotropin analogs. In addition, the truncation appears to markedly enhance the level of expression of the gonadotropin analogs in transfected Chinese hamster ovary ( $\mathrm{CHO}$ ) cells and, therefore, has the added practical benefit of improving yield and production efficiency.

Long-lived exogenous gonadotropins, such as hCG and eCG, often induce an immune reaction that may reduce the ovarian response of animals subject to repeated superovulatory protocols (Roy et al. 1999, Giordano et al. 2012). Recombinant human-based single-chain gonadotropin analogs may elicit a similar immune reaction when administered to sheep or other domestic species. Therefore, it would be advantageous to use dually active single-chain gonadotropin analogs based on the sequence of the ovine gonadotropin subunits to reduce the potential for development of neutralizing antibodies by developing.

To evaluate the role that the $\mathrm{FSH}: \mathrm{LH}$ activity ratio might have on the ovulatory response in sheep, we compared the superovulatory potential of two versions of the ovine-based dually active gonadotropin analogs. One single-chain dually active analog contained the fulllength forms of the ovine FSH and $\mathrm{LH} \alpha$ subunit and FSH and LH $\beta$ subunit, while the second contained a truncated form of oLH $\beta$ that lacked the C-terminal heptapeptide sequence. The second objective of this study was to determine the half-life of these dually active ovine-based chimeric gonadotropins. We proposed the hypothesis that a single-chain gonadotropin incorporating the functional domains of the ovine gonadotropin subunits would have both $\mathrm{LH}$ and FSH activities in sheep and induce follicular development and maturation and estradiol $\left(E_{2}\right)$ production. The truncated oLH $\beta$ subunit would display a lower LH activity, but a full FSH activity, when compared with dually active constructs that contained unabridged oLH $\beta$. We also hypothesized that the functional life of the ovine single-chain gonadotropins would be enhanced relative to pituitaryderived ovine gonadotropins.

\section{Materials and methods \\ Construction of single-chain gonadotropins and cell culture}

The single-chain gonadotropins were produced by transfecting $\mathrm{CHO}$ cells with gene constructs encoding the recombinant gonadotropins as described previously (Garcia-Campayo \& Boime 2001). The ovine (oFSH $\beta-C T P-O L H \beta-C T P-\alpha$; oFcLC $\alpha$ ), human (hFSH $\beta-\mathrm{CTP}-\mathrm{hLH} \beta-\mathrm{CTP}-\alpha$; hFCLC $\alpha$ ), and the truncated ovine single-chain gonadotropins with $\mathrm{FSH}$ and $\mathrm{LH}$ activity (oFSH $\beta-\mathrm{CTP}-\mathrm{OLH} \beta(\Delta \mathrm{T})-\mathrm{CTP}-\alpha ; \mathrm{oFCL}(\Delta \mathrm{T}) \mathrm{C} \alpha$ ) were constructed as described previously (Kanda et al. 1999, Garcia-Campayo \& Boime 2001). Briefly, genomic sequences encoding the $\mathrm{LH} \alpha-\mathrm{FSH} \alpha$ and $\mathrm{LH} \beta-\mathrm{FSH} \beta$ subunits are linked using the exon encoding the CTP of hCG $\beta$. The gene construct for the truncated gonadotropin, oFcL $(\Delta \mathrm{T})_{\mathrm{C} \alpha}$, encodes the complete oFSH $\alpha$ and oFSH $\beta$ subunit sequences and the oLH $\beta$ subunit lacking the carboxyl-terminal heptapeptide (Garcia-Campayo \& Boime 2001).

Transfected $\mathrm{CHO}$ cells were grown to confluency and the medium was collected and concentrated by centrifugation using an Amicon concentrator (Centricon Plus-70, Millipore Corp., Billerica, MA, USA). Human and ovine recombinant single-chain gonadotropin concentrations were measured using species-specific RIAs.

\section{Animals}

All experimental procedures involving the use of animals were conducted in accordance with NIH guidelines and were reviewed and approved by the Animal Use and Care Administrative Advisory Committee for the University of California, Davis. The study was conducted in late spring and early summer, a period when sheep at this latitude $\left(38^{\circ} \mathrm{N}\right)$ are in seasonal anestrus. Ewes were housed in an open sided barn with free access to alfalfa pellets and water.

\section{Cannulation}

One day before hormone administration, a polyethylene cannula (Intramedic PE 190, Clay Adams, Parsippany, NJ, USA) was inserted in the external jugular vein to facilitate hormone administration and blood collection. Tygon tubing 
was used as a protective sheath and the cannula and protective tubing were extended along the animal halter and lead rope to the exterior of the animal holding area. Using the exteriorized cannula permitted sample administration and blood collection without disturbing or physically contacting the animals.

\section{Immunization against gonadotropin-releasing hormone}

Antibodies directed against gonadotropin-releasing hormone (GNRH) were generated by actively immunizing castrated male sheep against a GNRH-carrier protein conjugate as described previously (Adams \& Adams 1986). The pool of antiGNRH sera used in these studies had high antibody titer $(0.1 \mathrm{ml}$ serum diluted 1:60 000 bound $35 \%$ of ${ }^{125}$ I-GNRH added in a final volume of $0.2 \mathrm{ml}$ ). Previous studies have demonstrated that the administration of GNRH antisera in the amounts used in this study blocks secretion of endogenous gonadotropins and prevents follicle development and ovulation (Sakurai et al. 1992, Lemke et al. 2008).

\section{Experimental design}

The experimental design is illustrated in Fig. 1. Twenty yearling black face ewes received progestogen-impregnated vaginal pessaries 10 days before experimentation. In order to eliminate the confounding effect of endogenous gonadotropins, animals were passively immunized against GNRH $24 \mathrm{~h}$ before pessary removal (PR). At PR, ewes ( $n=5 /$ group) were randomly

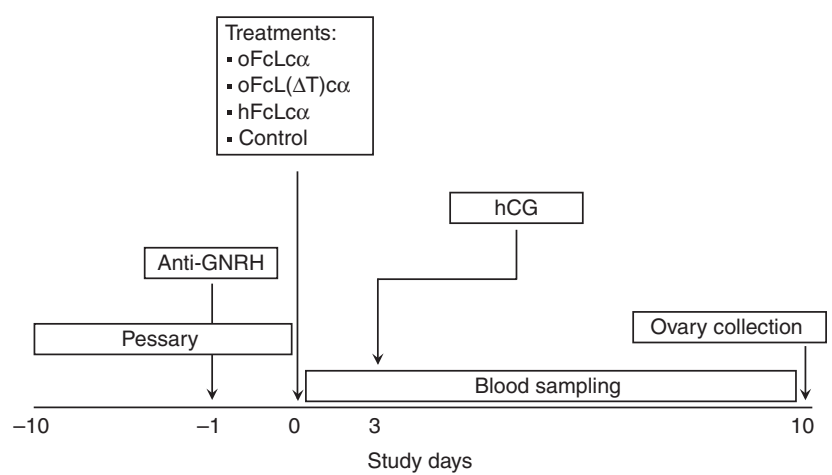

Figure 1 Experimental protocol. Estrous cycles of yearling ewes were synchronized using progestogen-containing vaginal pessaries. Animals were passively immunized against GNRH (150 ml/sheep, i.v.) 1 day before pessary removal (PR) to suppress gonadotropin secretion. Ewes lambs ( $n=5$ ewes/group) were treated with a single dose of either ovine single-chain gonadotropin with FSH and $\mathrm{LH}$ activities (oFCLC $\alpha$ ), human single-chain gonadotropin with FSH and LH activities (hFCLc $\alpha$ ), or ovine single-chain gonadotropins with $\mathrm{FSH}$ and $\mathrm{LH}$ activities lacking the carboxyl-terminus heptapeptide of the $\mathrm{LH} \beta$ subunit $(\mathrm{oFCL}(\Delta \mathrm{T}) \mathrm{C} \alpha$; $10 \mathrm{lU} / \mathrm{kg}$ of body weight, i.v.). Control animals received an equivalent protein concentration of conditioned media collected from nontransfected Chinese hamster ovary cells. Ovulation was induced by human chorionic gonadotropin (1000 IU, i.v.) administered 3 days after PR. Blood samples were collected at 6-h intervals for 6 days after analog administration and daily thereafter. Animals were killed and ovaries collected 11 days after PR. assigned to receive an i.v. injection $(10 \mathrm{IU} / \mathrm{kg})$ of either the ovine- or human-based dually active gonadotropin analogs (oFcLc $\alpha$, oFcL $(\Delta \mathrm{T}) \mathrm{C} \alpha$, or $\mathrm{hFCLC} \alpha$ respectively). Control animals $(n=5)$ received a similar dose of protein isolated from conditioned media from nontransfected $\mathrm{CHO}$ cells. Ovulation was induced $72 \mathrm{~h}$ after PR using $1000 \mathrm{IU}$ hCG (i.v.). Blood samples were collected before anti-GNRH injection and at 6 h-intervals during the 4-day-period following PR (day of PR is designated treatment day 0 ). Additional samples were collected every $12 \mathrm{~h}$ from days 4 to 8 and daily from days 8 to 10 . The blood samples were allowed to clot at $4{ }^{\circ} \mathrm{C}$ for $24 \mathrm{~h}$. Serum was collected after centrifugation and samples were stored at $-20{ }^{\circ} \mathrm{C}$ for later analysis. Ewes were killed at a local abattoir and ovaries were collected 11 days after PR. Ovaries were weighted, and number and size of follicles and corpora lutea $(\mathrm{CL})$ were recorded.

\section{Hormone analysis}

Serum concentrations of progesterone $\left(P_{4}\right)$ and $E_{2}$ were determined using previously validated RIAs (Adams et al. 1988, Sakurai et al. 1992). Serum concentrations of oFSH and oLH were determined using a RIA previously validated in our laboratory (Adams et al. 1979). The immunoactivity of hLH and $\mathrm{hFSH}$ in treated animals was determined using assay reagents obtained from the National Institute of Diabetes, Digestive and Kidney Diseases (NIDDKD). The hFSH RIA used NIDDK$\mathrm{hFSH}-\mathrm{l}-4$ for the iodination and hFSH antiserum NIDDK-antihFSH-6. The hLH RIA used NIDDK-hLH-I-SIAFP-I and antiserum NIDDK-anti-hLH-3.

\section{Statistical analysis}

The rate of gonadotropin clearance was analyzed using nonlinear regression. The $\mathrm{FSH}$ and $\mathrm{LH}$ clearance data were fitted to the equation $C(t)=A \mathrm{e}^{-\alpha t}$, where $C(t)$ is the serum concentration of hormone at time $t, t$ is time (h), A is the multiexponential coefficient, and $\alpha$ is the disposition rate constant. The best-fit parameters were obtained using the R Statistical Package (R Development Core Team 2005). Half-life was calculated as $T_{1 / 2}=($ elapsed time $\times \log 2) / \log$ (beginning amount/ending amount).

Analysis of $\mathrm{E}_{2}$ and $\mathrm{P}_{4}$ was performed using a repeated measures analysis including the fixed effects of time, treatment, and their interaction and the random effect of animal nested within the treatment $\times$ time. Differences between treatments within a time were determined by a Bonferroni's adjustment of the probability of difference calculated by the PDIFF option of SAS (SAS for Windows, version 9.3, SAS Institute, Inc., Cary, NC, USA). Analyses of disposition rate constant, gonadotropin half-life, area under the $E_{2}$ peak, duration of elevated $E_{2}$, time to the LH surge, and all ovarian measurements employed oneway ANOVA models with treatment as the sole fixed effect. Statistically significant differences between treatments were determined by $t$-test with the PDIFF option and Tukey's adjustment. Effects were considered to be significant when $P$ value was $\leq 0.05$. The mixed procedure in SAS was used to perform the statistical analyses described above. 

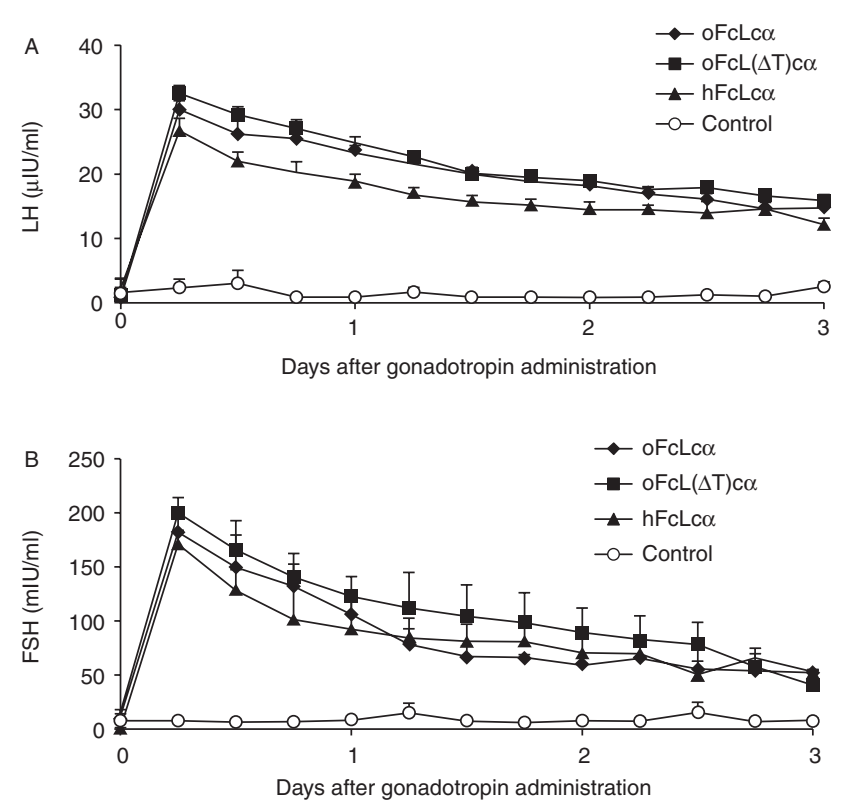

Figure 2 Disappearance of $\mathrm{LH}(\mathrm{A})$ and $\mathrm{FSH}(\mathrm{B})$ immunoactivities in ewe lambs treated with single-chain dually active gonadotropins. Control animals received an equivalent protein concentration of conditioned media collected from nontransfected Chinese hamster ovary cells. Animals received a single dose of either ovine single-chain gonadotropin with FSH and LH activities (oFcLc $\alpha$ ), human single-chain gonadotropins with $\mathrm{FSH}$ and $\mathrm{LH}$ activities ( $\mathrm{hFcLc} \alpha$ ), or ovine single-chain gonadotropins with $\mathrm{FSH}$ and $\mathrm{LH}$ activities lacking the carboxyl-terminus heptapeptide of the $\mathrm{LH} \beta$ subunit $(\mathrm{oFcL}(\Delta \mathrm{T}) \mathrm{C} \alpha$; $10 \mathrm{IU} / \mathrm{kg}$ of body weight, weight, i.v.).

\section{Clearance of the FSH and $\mathrm{LH}$ immunoactivities}

To quantify the $\mathrm{LH}$ and $\mathrm{FSH}$ immunoactivities in the serum of sheep treated with anti-GNRH and the dually active human- or ovine-based gonadotropin analogs, we used species-specific LH and FSH RIAs. One important feature of these assay systems is that they use antibodies that recognize conformational epitopes that are unique to the $\alpha \beta$ configuration. As a consequence, these assays serve as a measure of the ability of the single chains to fold into quaternary structures that are dimer like. As noted in Fig. 2 serum concentrations of oLH and oFSH are depressed in sheep treated with anti-GNRH and a control protein devoid of LH or FSH activity. Conversely, significant $\mathrm{LH}$ and $\mathrm{FSH}$ immunoactivities was evident in sheep receiving the human- or ovine-based gonadotropin analogs. Gonadotropin immunoactivity was elevated within $6 \mathrm{~h}$ of analog administration. Although immunoactivity gradually declined during the postinjection period, $\mathrm{LH}$ and $\mathrm{FSH}$ immunoactivities remained significantly elevated above control levels, even 3 days after administration of the gonadotropin analogs (Fig. 2).

A one-compartment model of clearance best describes the disappearance curves of $\mathrm{LH}$ and FSH immunoactivities. According to this model, the rate of clearance of LH immunoactivity of the human- and ovine-based gonadotropin analogs did not differ (Table 1). Similarly, the rate of clearance of FSH immunoactivity did not differ between analogs. The mean half-life of LH was significantly longer $(P<0.05)$ than the half-life of $\mathrm{FSH}$ immunoactivity (62.1 and $35.9 \mathrm{~h}$ respectively).

\section{Follicular development and $E_{2}$ production}

The effect of dually active single-chain gonadotropins on $E_{2}$ levels during the period after PR is illustrated in Fig. 3. endogenous gonadotropins. Antibody titer was expressed as the percentage of ${ }^{125} \mathrm{I}-\mathrm{GNRH}$ bound to a 1:1000 dilution of serum. Anti-GNRH levels were high at PR $\left(44.7 \%\right.$ of ${ }^{125}$ I-GNRH bound) and declined progressively thereafter. The level of antiGNRH titer 10 days after PR was $25.6 \%$. The antibody titer decreased gradually $(P=0.001)$ over the period of the study but did not differ among treatment groups $(P=0.48)$.

The ability of anti-GNRH to suppress gonadotropin secretion and ovarian activity was demonstrated in the animals receiving conditioned media from nontransfected $\mathrm{CHO}$ cells (control group). Gonadotropin concentrations were maintained at basal levels during the period after PR (Fig. 2). Serum $E_{2}$ concentrations did not increase in response to $P R$ (Fig. 3) and $P_{4}$ concentrations were maintained at basal levels during the post-hCG period (Fig. 4). In addition, no CLs or follicles larger than $4 \mathrm{~mm}$ were noted on the ovaries of these animals (Fig. 5).

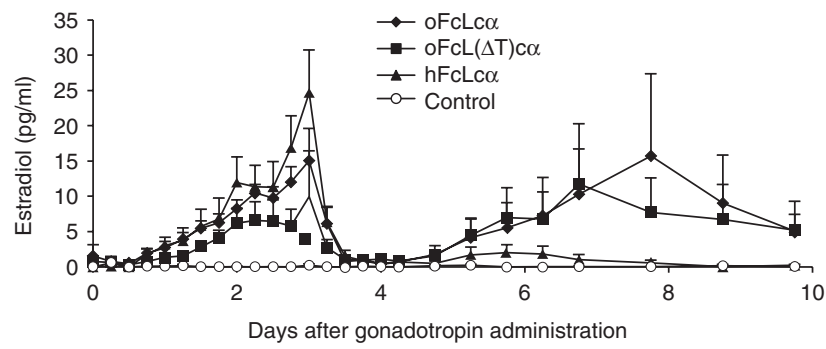

Figure 3 Serum estradiol concentrations ( $\mathrm{pg} / \mathrm{ml}$ ) during the study period in ewes receiving single-chain gonadotropins with $\mathrm{FSH}$ and $\mathrm{LH}$ activities (10 IU/kg of body weight, i.v.) at the time of pessary removal. Ewe lambs received either ovine single-chain gonadotropin with FSH and $\mathrm{LH}$ activities (oFcLc $\alpha$ ), ovine single-chain gonadotropins with FSH and $\mathrm{LH}$ activities lacking the carboxyl-terminus heptapeptide of the $\mathrm{LH} \beta$ subunit $(\mathrm{oFCL}(\Delta \mathrm{T}) \mathrm{C} \alpha$ ), or human single-chain gonadotropins with $\mathrm{FSH}$ and $\mathrm{LH}$ activities ( $\mathrm{hFCLC} \alpha$ ). Ewes in the control group received conditioned media from non-transfected Chinese hamster ovary cells. The preovulatory surge of $\mathrm{LH}$ was simulated by administration of hCG (1000 IU, i.v.) 3 days after gonadotropin treatment. 


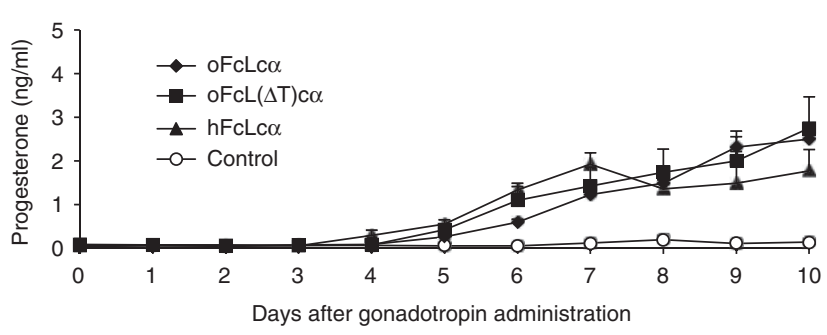

Figure 4 Serum progesterone concentrations $(\mathrm{ng} / \mathrm{ml})$ during the full study period in ewe lambs receiving single-chain gonadotropins with FSH and $\mathrm{LH}$ activities (10 IU/kg of body weight, i.v.) at the time of pessary removal. Animals received either ovine single-chain gonadotropin with FSH and $\mathrm{LH}$ activities (oFCLC $\alpha$ ), ovine single-chain gonadotropins with $\mathrm{FSH}$ and $\mathrm{LH}$ activities lacking the carboxylterminus heptapeptide of the $\mathrm{LH} \beta$ subunit $(\operatorname{oFCL}(\Delta \mathrm{T}) \mathrm{C} \alpha)$, or human single-chain gonadotropins with FSH and LH activities (hFcLc $\alpha$ ). Ewes in the control group received conditioned media containing an equivalent amount of protein from nontransfected Chinese hamster ovary cells. The preovulatory surge of LH was simulated by administration of hCG (1000 IU, i.v.) 3 days after gonadotropin treatment.

There was a highly significant effect $(P<0.001)$ of the treatments on serum $E_{2}$ concentrations. $E_{2}$ concentrations were maintained at basal levels in ewe lambs receiving control protein devoid of gonadotropin activity. In contrast, $E_{2}$ levels increased within 2 days of administration of recombinant gonadotropin. As the animals were treated with anti-GNRH to block the secretion of endogenous gonadotropins, 1000 IU of hCG was used to trigger ovulation 3 days after gonadotropin treatment. Administration of hCG rapidly terminated the preovulatory rise of $E_{2}$ and the concentration of this hormone returned to basal levels 1 day after hCG treatment. A secondary, post-ovulatory increase in $E_{2}$ was observed in animals treated with ofcLc $\alpha$ and $\operatorname{oFcL}(\Delta \mathrm{T}) \mathrm{c} \alpha$ (Fig. 3). However, no such secondary increase in $E_{2}$ was noted in ewes receiving the humanbased gonadotropin analog ( $\mathrm{hFCLC} \alpha)$.

As noted earlier, secretion of $\mathrm{P}_{4}$ was maintained at low levels and no CLs were evident in control ewes receiving anti-GNRH and gonadotropin-free protein (control group). Conversely, secretion of $\mathrm{P}_{4}$ was significantly increased during the post-hCG period in all ewes receiving the single-chain gonadotropin constructs (Fig. 4). Similarly, multiple CLs were evident on the ovaries of ewes receiving the gonadotropin analogs. These results demonstrate that single-chain gonadotropins promote follicular development and maturation and the LH surge simulated by hCG-induced ovulation and formation of CLs in yearling ewes.

\section{Trophic ovarian response}

The results above demonstrated the activity of the singlechain gonadotropins on ovarian steroidogenesis and follicular development. The in vivo activity of the single-chain gonadotropins could also be measured by its trophic effect on the ovaries. As illustrated in Fig. 5, the final ovarian weight in animals treated with singlechain gonadotropins was significantly greater $(P<0.05)$ than the ovarian weight noted in control animals. The number of follicles $>4 \mathrm{~mm}$ at 11 days post-PR was also increased $(P<0.05)$ in ewes treated with $\mathrm{hFcLc} \alpha$, oFcLc $\alpha$, and oFcL $(\Delta \mathrm{T}) \mathrm{C} \alpha$ compared with the control group (mean \pm S.E.M.: $3.0 \pm 1.3,3.4 \pm 1.4,4.2 \pm 1.6$, and $0.0 \pm 0.0$ respectively). However, there was no significant difference in the number of these follicles between single-chain gonadotropin analogs. The augmentation of ovarian weight in the animals receiving gonadotropins can be attributed to the increase in number of CLs and a considerable increase in the number of large follicles.

\section{Discussion}

The data presented here demonstrate that the recombinant single-chain form of the ovine gonadotropic hormones has high potency in sheep and expresses both $\mathrm{LH}$ and $\mathrm{FSH}$ activities. In addition, we have demonstrated that these gonadotropin analogs are long lived and a single administration is sufficient to promote development and maturation of multiple follicles. Endogenous gonadotropins are key regulators of ovarian function and exogenous gonadotropins are often used in assisted reproductive technologies to facilitate the propagation of animals with superior phenotypic traits or outstanding genetic potential. The dual activity and long-lived nature of the chimeric gonadotropins used in this study indicate that ovine

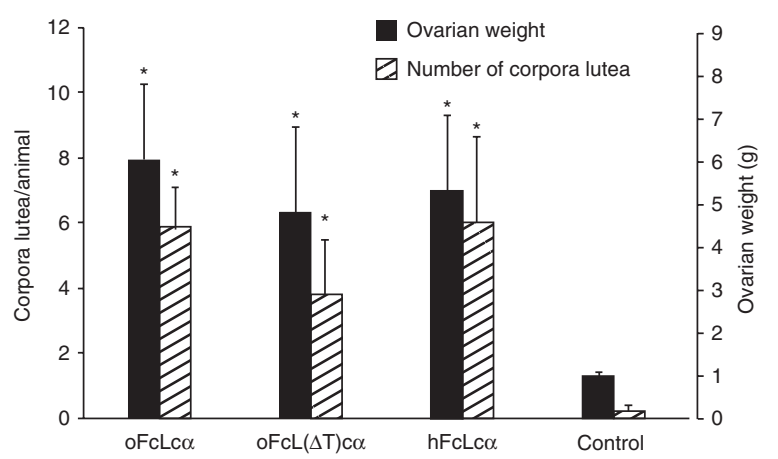

Figure 5 Number of corpora lutea (mean \pm s.E.M.) and ovarian weights (in (g); mean \pm S.E.M.) in animals treated with recombinant single-chain ovine and human gonadotropins with FSH and $\mathrm{LH}$ activities $(10 \mathrm{IU} / \mathrm{kg}$ of body weight, i.v.) at the time of pessary removal. Ewe lambs were treated with either ovine single-chain gonadotropin with FSH and $\mathrm{LH}$ activities (oFcLC $\alpha$ ), ovine single-chain gonadotropins with $\mathrm{FSH}$ and $\mathrm{LH}$ activities lacking the carboxyl-terminus heptapeptide of the $\mathrm{LH} \beta$ subunit $(\mathrm{oFcL}(\Delta \mathrm{T}) \mathrm{c} \alpha$ ), or human single-chain gonadotropins with $\mathrm{FSH}$ and $\mathrm{LH}$ activities ( $\mathrm{hFCLC} \boldsymbol{\alpha}$ ). Ewes in the control group received conditioned media from nontransfected Chinese hamster ovary cells. The preovulatory surge of LH was simulated by administration of hCG $(1000 \mathrm{IU}$, i.v. $) 3$ days after gonadotropin treatment. ${ }^{*}$ Treated groups are significantly different $(P<0.05)$ from the control group. 
Table 1 Disappearance rates and half-life of FSH and LH immunoactivities of the single-chain gonadotropins with FSH and $\mathrm{LH}$ activities.

\begin{tabular}{lll}
\hline Gonadotropin & $\boldsymbol{\alpha}^{\mathrm{a}}$ & $\boldsymbol{T}_{\mathbf{1 / 2}}^{\mathrm{b}}(\mathrm{h})$ \\
\hline FSH & & \\
oFcLC $\alpha$ & $0.024^{*}$ & $42.0^{*}$ \\
OFcL $(\Delta \mathrm{T}) \mathrm{C} \alpha$ & $0.020^{*}$ & $37.0^{*}$ \\
hFcLC $\alpha$ & $0.016^{*}$ & $28.8^{*}$ \\
Control & $0.003^{+}$ & $\mathrm{ND}$ \\
LH & & \\
oFcLc $\alpha$ & $0.011^{*}$ & $64.1^{*}$ \\
oFcL $(\Delta \mathrm{T}) \mathrm{C} \alpha$ & $0.011^{*}$ & $64.0^{*}$ \\
hFcLC $\alpha$ & $0.011^{*}$ & $58.3^{*}$ \\
Control & $0.004^{+}$ & $\mathrm{ND}$ \\
\hline
\end{tabular}

$\mathrm{ND}$, not determined. Different symbols within the same assay (FSH or LH immunoreactivity) and column indicate ${ }^{*,+} P<0.05$.

${ }^{a}$ Disposition rate constant $(\alpha)$. The FSH and LH data were fitted to the equation $C(t)=A \mathrm{e}^{-\alpha t}$, where $C(t)$ is the serum concentration of hormone at time $t, t$ is time (h), $\mathrm{A}$ is the multiexponential coefficient. ${ }^{\mathrm{b}}$ Half-life (h): $T_{1 / 2}=\ln _{\mathrm{e}} 2 / \alpha$.

single-chain gonadotropins may be useful alternatives to tissue-derived gonadotropins in superovulation protocols for domestic animals.

Our previous studies have demonstrated that the single-chain analogs of human $\mathrm{LH}$ and FSH have a lengthy functional life in sheep and are much longer lived in sheep than ovine $\mathrm{LH}$ and FSH obtained from pituitary tissue (Rodriguez \& Adams, unpublished observations). Our findings regarding gonadotropin clearance demonstrate that the single-chain gonadotropin constructs with dual activity are extraordinarily long lived in sheep. Importantly, both the ovine- and human-based dually active analogs exhibited this longlived character. According to the one-compartment clearance model used in our calculations, the half-lives of the FSH immunoactivity of oFcLc $\alpha$, oFcL $(\Delta \mathrm{T}) \mathrm{C} \alpha$, and $\mathrm{hFCLC} \alpha$ were $42.0,37.0$, and $28.8 \mathrm{~h}$ respectively. While the half-life of the $\mathrm{LH}$ immunoactivity for the same constructs was $64.1,64.0$, and $58.3 \mathrm{~h}$ respectively. In comparison, the published estimates of clearance of pituitary-derived ovine FSH and LH in sheep are 102 and 43 min respectively (Akbar et al. 1974). The long-lived nature of the recombinant gonadotropin analogs used in this study is likely due, in large part, to the addition of the CTP linker sequence. Indeed, Devroey et al. (2004) reported that adding the CTP to the $\beta$ subunit of recombinant FSH increased its half-life two- to threefold. The size and extensive $O$-linked glycosylation that is characteristic of the CTP is thought to retard hepatic and renal clearance (Matzuk et al. 1990). The longevity of the single-chain constructs has important practical implications, because a single injection of these potent analogs will induce a profound superovulatory response. In contrast, conventional pituitary-derived gonadotropins must be administered repeatedly over a 2-3 days period to elicit a comparable ovarian response (Takagi et al. 2001).

$E_{2}$ production is a useful measure of the coordinated and combined action of FSH and $\mathrm{LH}$. $\mathrm{LH}$ stimulates the production of androgens, such as androstenedione and testosterone, by thecal cells (Nahum et al. 1995) while $\mathrm{FSH}$ is mainly responsible for the activation of aromatase, the enzyme in the granulosa cells that converts androgens to estrogens. In an anti-GNRH sheep model, similar to the one used in our studies, Lemke et al. (2008) demonstrated that the single-chain gonadotropins with $\mathrm{hFSH}$ activity promoted follicular growth but not $\mathrm{E}_{2}$ production. Conversely, single-chain gonadotropins with $\mathrm{LH}$ activity did not induce follicular growth or $\mathrm{E}_{2}$ production (Lemke et al. 2008). However, concurrent treatment with single-chain analogs of both $\mathrm{hLH}$ and $\mathrm{hFSH}$ resulted in a marked increase in $\mathrm{E}_{2}$ secretion. These observations demonstrate that $\mathrm{FSH}$ alone induces follicle development, but the synergy between $\mathrm{FSH}$ and $\mathrm{LH}$ is necessary for $\mathrm{E}_{2}$ synthesis.

The $\mathrm{P}_{4}$ and $\mathrm{E}_{2}$ response to the single-chain gonadotropin analogs observed in our study was lower than the response observed by Lemke et al. (2008). This discrepancy can be explained by the season when these animals received single-chain gonadotropins. In the study by Lemke et al. (2008), ewes were treated during late fall and early winter when reproduction is at its maximum. In our study, in order to test whether these chimeric gonadotropins would be able to promote follicular development and $E_{2}$ production in ewes in anestrus, chimera administration was conducted during late spring and early summer when sheep at this latitude $\left(38^{\circ} \mathrm{N}\right)$ are in seasonal anestrus. This may also explain the fact that Lemke et al. observed: a more pronounced $\mathrm{E}_{2}$ production in ewes treated with dually active chimeric gonadotropins and increased numbers of $\mathrm{CL}$ and ovarian weight. The administration of highly purified porcine pituitary extract to ewes in the breeding season significantly increases the number of recovered embryos than that during the nonbreeding season (Cueto et al. 2011). In addition, the effect of season on the ovulatory response of ewes treated with pregnant mare serum is lowest in the spring and highest in the fall (Gherardi \& Lindsay 1980).

In our model, ewes treated with GNRH anti-sera were used to test the efficacy of ovine single-chain gonadotropins on ovarian activity. We found that the singlechain ovine gonadotropin analogs with dual activity were as potent as the comparable human-based analog in induction of follicular development and maturation, $\mathrm{E}_{2}$ production, and $\mathrm{CL}$ formation. In addition, the apparent bioactivity of the full-length and truncated versions of the ovine gonadotropin analogs was comparable, both in terms of superovulatory potential and with regard to levels of preovulatory $E_{2}$ production. An interesting aspect of the hormonal response in the animals receiving the ovine-based analogs was the occurrence of a secondary post-ovulatory $E_{2}$ surge. It has been reported that atretic follicles do not produce significant amounts of $E_{2}$ (Henderson et al. 1984, McNatty et al. 1984) and that they cannot respond to 
exogenous gonadotropin stimulation by eCG to produce $E_{2}$ (McNatty et al. 1982); therefore, this is probably a result of the maturation of a second cohort of follicles after ovulation induced by the long-lived FSH and LH activities of the single-chain gonadotropins. Similar postovulatory surges of $E_{2}$ are evident in cattle in which superovulation was induced by use of eCG (Kaneko et al. 1992). We also noted a similar post-ovulatory rise in $E_{2}$ in sheep treated with dually active human gonadotropin analogs (Lemke et al. 2008).

Collectively, these data demonstrate that the singlechain analogs of the ovine gonadotropins are active in sheep. The superovulatory response effected by the ovine chimeric gonadotropin hormones is a clear illustration of their FSH activity, and their ability to increase $E_{2}$ production is a good evidence that the analogs express LH activity as well. The slow rate of clearance of these chimeric hormones gives them a long functional life and obviates the repetitive administration of $\mathrm{FSH}$ that is characteristic of most superovulation protocols. In addition, use of the analogs with dual activity assures concurrent activation of $\mathrm{LH}$ and $\mathrm{FSH}$ receptors in ovulatory follicles and facilitates the follicular secretion of $E_{2}$ required to induce ovulation. Dually active chimeric gonadotropins built on the ovine gonadotropin framework are less likely to induce an immune response in sheep, a feature of the ovine-based constructs that may permit their repeated use. Indeed, the purity, production efficiency, longevity, and dual activity of the single-chain ovine gonadotropin analogs makes these unique recombinant gonadotropins an effective alternative to placental or pituitary-derived gonadotropins in assisted reproductive technologies.

\section{Declaration of interest}

The authors declare that there is no conflict of interest that could be perceived as prejudicing the impartiality of the research reported.

\section{Funding}

This work was supported by the National Research Initiative Competitive grant number 2005-35203-16274 from the USDA Cooperative State Research, Education, and Extension Service, Animal Reproduction Program and by the California Agricultural Experiment Station.

\section{Acknowledgements}

The authors thank Laura Dao and Benjamin Renquist for the technical assistance.

\section{References}

Adams TE \& Adams BM 1986 Gonadotrope function in ovariectomized ewes actively immunized against gonadotropin-releasing hormone (GnRH). Biology of Reproduction 35 360-367. (doi:10.1095/bioIreprod35.2.360)
Adams TE, Wagner TO, Sawyer HR \& Nett TM 1979 GnRH interaction with anterior pituitary. II. Cyclic AMP as an intracellular mediator in the GnRH activated gonadotroph. Biology of Reproduction 21 735-747. (doi:10. 1095/biolreprod21.3.735)

Adams TE, Quirke JF, Hanrahan JP, Adams BM \& Watson JG 1988 Gonadotrophin secretion during the periovulatory period in Galway and Finnish Landrace ewes and Finnish Landrace ewes selected for high ovulation rate. Journal of Reproduction and Fertility 83 575-584. (doi:10. 1530/jrf.0.0830575)

Akbar AM, Nett TM \& Niswender GD 1974 Metabolic clearance and secretion rates of gonadotropins at different stages of the estrous cycle in ewes. Endocrinology 94 1318-1324. (doi:10.1210/endo-94-5-1318)

Bouloux PM, Handelsman DJ, Jockenhövel F, Nieschlag E, Rabinovici J, Frasa WL, de Bie JJ, Voortman G, Itskovitz-Eldor J \& FSH-CTP study group 2001 First human exposure to FSH-CTP in hypogonadotrophic hypogonadal males. Human Reproduction 16 1592-1597. (doi:10.1093/ humrep/16.8.1592)

Callesen H, Greve T \& Hyttel P 1987 Premature ovulations in superovulated cattle. Theriogenology 28 155-166. (doi:10.1016/0093691X(87)90263-9)

Cueto MI, Gibbons AE, Pereyra-Bonnet F, Silvestre P \& González-Bulnes A 2011 Effects of season and superovulatory treatment on embryo yields in fine-wool Merinos maintained under field conditions. Reproduction in Domestic Animals 46 770-775. (doi:10.1111/j.1439-0531.2010.01738.x)

Devroey P, Fauser BC, Platteau P, Beckers NG, Dhont M \& Mannaerts BM 2004 Induction of multiple follicular development by a single dose of long-acting recombinant follicle-stimulating hormone (FSH-CTP, corifollitropin alfa) for controlled ovarian stimulation before in vitro fertilization. Journal of Clinical Endocrinology and Metabolism 89 2062-2070. (doi:10.1210/jc.2003-031766)

Galli C, Duchi R, Crotti G, Turini P, Ponderato N, Colleoni S, Lagutina I \& Lazzari G 2003 Bovine embryo technologies. Theriogenology 59 599-616. (doi:10.1016/S0093-691X(02)01243-8)

Garcia-Campayo V \& Boime I 2001 Independent activities of FSH and LH structurally confined in a single polypeptide: selective modification of the relative potencies of the hormones. Endocrinology 142 5203-5211. (doi:10.1210/endo.142.12.8541)

Gherardi PB \& Lindsay DR 1980 The effect of season on the ovulatory response of Merino ewes to serum from pregnant mares. Journal of Reproduction and Fertility 60 425-429. (doi:10.1530/jrf.0.0600425)

Giordano JO, Wiltbank MC \& Fricke PM 2012 Humoral immune response in lactating dairy cows after repeated exposure to human chorionic gonadotropin. Theriogenology 78 218-224. (doi:10.1016/j.theriogenology.2012.02.003)

Henderson KM, Franchimont P, Charlet-Renard C \& McNatty KP 1984 Effect of follicular atresia on inhibin production by bovine granulosa cells in vitro and inhibin concentrations in the follicular fluid. Journal of Reproduction and Fertility 72 1-8. (doi:10.1530/jrf.0.0720001)

Kanda M, Jablonka-Shariff A, Sato A, Pixley MR, Bos E, Hiro'oka T, Ben-Menahem D \& Boime I 1999 Genetic fusion of an $\boldsymbol{\alpha}$-subunit gene to the follicle-stimulating hormone and chorionic gonadotropin- $\beta$ subunit genes: production of a bifunctional protein. Molecular Endocrinology 13 1873-1881. (doi:10.1210/mend.13.11.0372)

Kaneko H, Watanabe G, Taya K \& Sasamoto S 1992 Changes in peripheral levels of bioactive and immunoreactive inhibin, estradiol-17 $\beta$, progesterone, luteinizing hormone, and follicle-stimulating hormone associated with follicular development in cows induced to superovulate with equine chorionic gonadotropin. Biology of Reproduction 47 76-82. (doi:10.1095/biolreprod47.1.76)

Kanitz W, Becker F, Schneider F, Kanitz E, Leiding C, Nohner H-P \& Pöhland R 2002 Superovulation in cattle: practical aspects of gonadotropin treatment and insemination. Reproduction, Nutrition, Development 42 587-599. (doi:10.1051/rnd:2002045)

Lemke EP, Adams BM, Jablonka-Shariff A, Boime I \& Adams TE 2008 Single-chain human gonadotropin analogs induce follicle development in sheep. Journal of Endocrinology 196 593-600. (doi:10.1677/JOE-070473)

Matzuk MM, Hsueh AJ, Lapolt P, Tsafriri A, Keene JL \& Boime I 1990 The biological role of the carboxyl-terminal extension of human chorionic gonadotropin [corrected] $\beta$-subunit. Endocrinology 126 376-383. (doi:10.1210/endo-126-1-376) 
McNatty KP, Gibb M, Dobson C, Ball K, Coster J, Heath D \& Thurley DC 1982 Preovulatory follicular development in sheep treated with PMSG and/or prostaglandin. Journal of Reproduction and Fertility 65 111-123. (doi:10.1530/jrf.0.0650111)

McNatty KP, Heath DA, Henderson KM, Lun S, Hurst PR, Ellis LM, Montgomery GW, Morrison L \& Thurley DC 1984 Some aspects of thecal and granulosa cell function during follicular development in the bovine ovary. Journal of Reproduction and Fertility 72 39-53. (doi:10. 1530/jrf.0.0720039)

Nahum R, Thong KJ \& Hillier SG 1995 Metabolic regulation of androgen production by human thecal cells in vitro. Human Reproduction 10 75-81. (doi:10.1093/humrep/10.1.75)

Opavsky MA \& Armstrong DT 1989 Effects of luteinizing hormone on superovulatory and steroidogenic responses of rat ovaries to infusion with follicle-stimulating hormone. Biology of Reproduction 41 15-25. (doi:10.1095/biolreprod41.1.15)

R Development Core Team 2005 R: A language and environment for statistical computing. In R Foundation for Statistical Computing, Vienna, Austria. ISBN 3-900051-07-0, URL, http://www.R-project.org.

Roy F, Maurel MC, Combes B, Vaiman D, Cribiu EP, Lantier I, Pobel T, Delétang F, Combarnous Y \& Guillou F 1999 The negative effect of repeated equine chorionic gonadotropin treatment on subsequent fertility in Alpine goats is due to a humoral immune response involving the major histocompatibility complex. Biology of Reproduction $\mathbf{6 0}$ 805-813. (doi:10.1095/biolreprod60.4.805)

Sakurai H, Adams BM \& Adams TE 1992 Pattern of gonadotropin-releasing hormone $(\mathrm{GnRH})$-like stimuli sufficient to induce follicular growth and ovulation in ewes passively immunized against GnRH. Biology of Reproduction 47 177-184. (doi:10.1095/biolreprod47.2.177)

Sugahara T, Sato A, Kudo M, Ben-Menahem D, Pixley MR, Hsueh AJ \& Boime I 1996 Expression of biologically active fusion genes encoding the common $\alpha$ subunit and the follicle-stimulating hormone $\beta$ subunit. Role of a linker sequence. Journal of Biological Chemistry 271 10445-10448. (doi:10.1074/jbc.271.18.10445)

Takagi M, Kim IH, Izadyar F, Hyttel P, Bevers MM, Dieleman SJ, Hendriksen PJ \& Vos PL 2001 Impaired final follicular maturation in heifers after superovulation with recombinant human FSH. Reproduction 121 941-951. (doi:10.1530/rep.0.1210941)

Received 4 February 2014

First decision 3 March 2014

Revised manuscript received 2 May 2014

Accepted 7 May 2014 